\title{
A study on the growth of AIN single crystals
}

\author{
Seung-Min $\mathrm{Kang}^{\dagger}$ \\ Department of Advanced Materials Science and Engineering, Hanseo University, Seosan 356-820, Korea \\ (Received October 11, 2013) \\ (Revised November 11, 2013) \\ (Accepted November 22, 2013)
}

Abstract Recently, it has been interested much that AlN (Aluminum Nitride) crystals can be applied to UV LEDs and high power devices as like $\mathrm{GaN}$ and $\mathrm{SiC}$ crystals. The reports about commercial grade of AlN wafers in the world have been absent, however several results for growth of large size of AlN single crystals have been reported from abroad. In this report, the result of AlN single crystals of a diameter of about $8 \mathrm{~mm}$ grown are reported. Optical microscopic characterization was applied to observe the form of the crystals and the crystal quality was evaluated by FWHM measurement by DCXRD rocking curve analysis.

Key words AlN, Single crystals, Morphology, PVT (Physical Vapor Transport), Growth facets

\section{AIN 단결정 성장에 관한 연구}

강승민

한서대학교 신소재공학과, 서산, 356-820

(2013년 10월 11일 접수)

(2013년 11월 11일 심사완료)

(2013년 11월 22일 게재확정)

요 약 최근 관심이 높아지고 있는 $\mathrm{GaN}, \mathrm{SiC}$ 단결정과 함께 자외선 $\mathrm{LED}$ 및 전력 반도체 용 기판 소재로서 응용성이 높은 질화갈륨(AlN, Aluminum Nitride) 단결정을 성장하였다. 아직 상용화된 $\mathrm{AlN}$ 기판은 없지만, 단결정 성장에 대한 연구 가 이루어지고 있다. 본 연구에서는 국내 최초로 $\mathrm{AlN}$ 단결정의 성장 결과 직경 약 $8 \mathrm{~mm}$ 의 결정을 성장하였다. 성장된 단 결정은 광학현미경으로 관찰하였으며, $\mathrm{DCXRD}$ 를 통하여 결정성을 평가한 결과를 보고하고자 한다.

\section{1. 서 론}

현재 전 세계적으로 그린에너지 정책과 에너지 절감을 위한 노력이 이루어지고 있는 가운데, 전통적인 백열 전 구를 대체할 수 있는 LED 조명 산업이 발전됨에 따라, 전력의 절감을 위한 $\mathrm{GaN}, \mathrm{SiC}$ 등의 반도체 소자들이 개발되고 있다. 이와 함께, $\mathrm{AlN}$ 소재 또한 $6.2 \mathrm{eV}$ 의 밴 드갭 에너지 특성 때문에 고전력 반도체 및 기존의 자외 선 램프를 대체할 수 있는 자외선 LED로서의 응용도 및 시장성이 증가되면서 연구가 많이 진행되고 있다. 그 러나, $\mathrm{AlN}$ 단결정은 증발온도가 대기압하에서 $2450^{\circ} \mathrm{C}$ 정도로 높아서 PVT(Physical Vapor Transport) 법을 이

\footnotetext{
Corresponding author

Tel: +82-41-660-1446

Fax: +82-41-688-1343

E-mail: smkang@hanseo.ac.kr
}

용하고 $\mathrm{SiC}$ 결정을 종자결정으로 한 이종종자 성장법을 적용하여 2 인치 크기의 결정을 얻어내기는 하였으나, 품 질은 아직 만족할만한 정도에 미치지 못하고 있다[1]. 본 연구는 국내에서는 처음으로 미소 크기 $(1 \sim 3 \mathrm{~mm})$ 의 $\mathrm{AlN}$ 단결정을 사용하여 PVT 법을 적용하여 성장시킨 직경 $8 \mathrm{~mm}$ 의 질화알루미늄(AlN) 단결정의 결정성을 DCXRD(Double Crystal X-Ray Diffractometry)로 분석 한 결과에 대하여 보고하고자 한다.

\section{2. 실 험}

$\mathrm{PVT}$ 공정을 적용하여 $\mathrm{AlN}$ 단결정을 성장하였으며[24], 성장된 결정은 미소 크기의 $\mathrm{AlN}$ 단결정을 종자결정 으로 사용하였다. 종자결정은 도가니 상부의 결정이 성 장되는 위치에 물리적으로 고정시켰고, 이를 일정 성장 
조건하에서 성장할 수 있도록 유지하였다. $\mathrm{AlN}$ 단결정 의 성장 온도는 $1950 \sim 2150^{\circ} \mathrm{C}$ 에서 온도편차 $2^{\circ} \mathrm{C}$ 이내로 제어되는 온도제어시스템을 이용하여 제어하였으며, 성 장 압력은 1 500 torr의 범위에서 제어하였다. 압력 제어 를 위하여 질소 $\left(\mathrm{N}_{2}\right)$ 가스를 $20 \sim 100 \mathrm{sccm}$ 유량으로 조절 하여 주입하였으며, 편차 범위 약 10 torr 이내의 범위에 서 제어될 수 있도록 하였다. AlN 단결정을 성장하기 위한 원료로는 Tokuyama 사(일본)의 AlN 분말(순도: $99.95 \%, \mathrm{D}_{50}:<1.0 \mu \mathrm{m}$ ) 원료를 사용하였으며 성장온도 에 도달하기 전 단계에서 하소와 소결을 진행할 수 있는 성장 프로그램을 개발하여 적용하였다. 결정의 성장시간 은 120 시간 행하였다. 종자결정은 모양이 불규칙하고 다 면체의 형상을 갖고 있어 이를 물리적으로 고정하기 위 하여 그라파이트 치구를 이용하여 물리적인 방법으로 부 착하여 결정 성장용 도가니에 장착하여 성장하였다. AlN 단결정을 성장하기 위하여 사용한 도가니는 그라파 이트 소재로 용기부와 뚜껑부로 나누어 제작 조립하였고, 총 외경 $90 \mathrm{~mm}$, 총 높이는 $125 \mathrm{~mm}$ 로 하였다. 도가니는 그라파이트 단열재를 사용하여 보온되고 단열될 수 있도 록 하였으며, 석영으로 제작된 반응관 내에 장착하고, 반 응관 외부에 설치된 고주파 가열 코일(Radio Freqquency heating coil)의 내에 위치시켜, 고주파유도가열 장치를 이용하여 가열하였다. 고주파유도가열 장치의 주파수는 $20 \mathrm{kHz}$ 로 저주파수 대역의 가열 방식을 택하였다. 성장 된 결정은 광학 현미경을 이용하여 크기를 측정하였고, 성장된 결정을 $\mathrm{C}$ 면을 기준으로 절단하고 절단된 결정 과 성장된 면(C 면)에 대하여 DCXRD 분석을 행하여 FWHM(Full Width at Half Maximum)을 측정하여 고 찰하였다.

\section{3. 결과 및 고찰}

Fig. 1과 Fig. 2에 본 연구에서 사용한 종자결정을 나 타내었다. Fig. 3에 성장된 결정의 광학현미경 사진을 나타내었다. 결정을 성장하기 위한 종자결정은 임의로 생성된 핵으로부터 결정의 우선 성장 방향으로 성장된 결정이었다. $\mathrm{AlN}$ 결정은 육각기둥의 형태로 성장하는 특성이 있으나, 임의로 형성된 핵으로부터 성장되는 결 정은 Fig. 1과 같이 a축 방향으로 성장되어진 결과를 얻 었다[2, 3]. Fig. 3에 보인 $\mathrm{AlN}$ 결정의 평균 성장 속도 는 약 $20 \sim 30 \mu \mathrm{m} / \mathrm{hr}$ 였으며, facet 이 발달하는 것으로 보아 결정 성장 계면은 평형상태에서 성장되었음을 알 수 있다. 즉, $\mathrm{Al}$ 원자와 $\mathrm{N}$ 원자들이 성장계면에서 합성 되어 결정이 성장하는 평형조건에서 성장이 이루어지고 있음을 알 수 있다. 그러나, Fig. 2의 종자결정에 나타나 있는 facet과 Fig. 3의 결과를 비교해 보면, 종자결정으

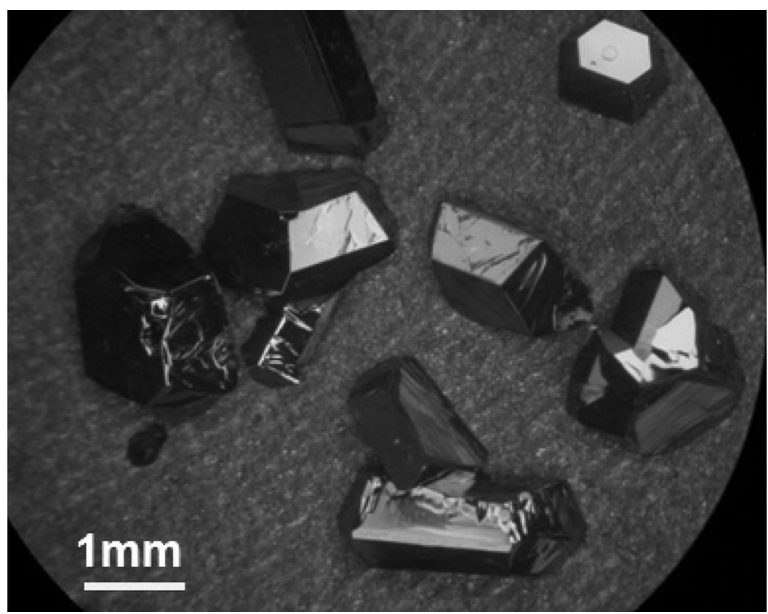

Fig. 1. Naturally grown AIN crystals which was used as seed for growing a bigger crystal shown in Fig. 2 in the next step growth.

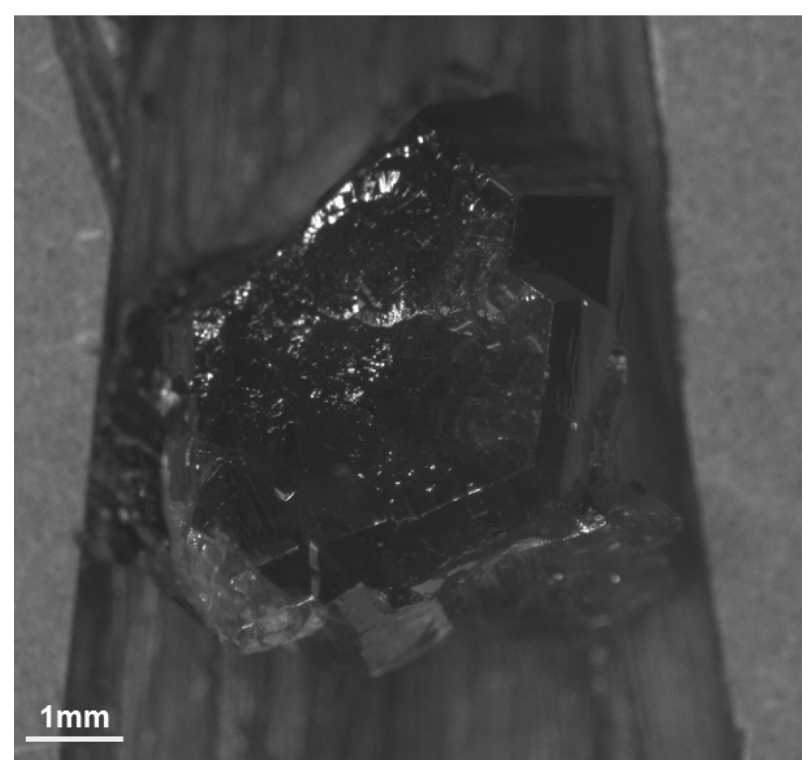

Fig. 2. Micrograph of seed crystal having a size of about $5 \mathrm{~mm}$ used in the growth of large AlN crystal.

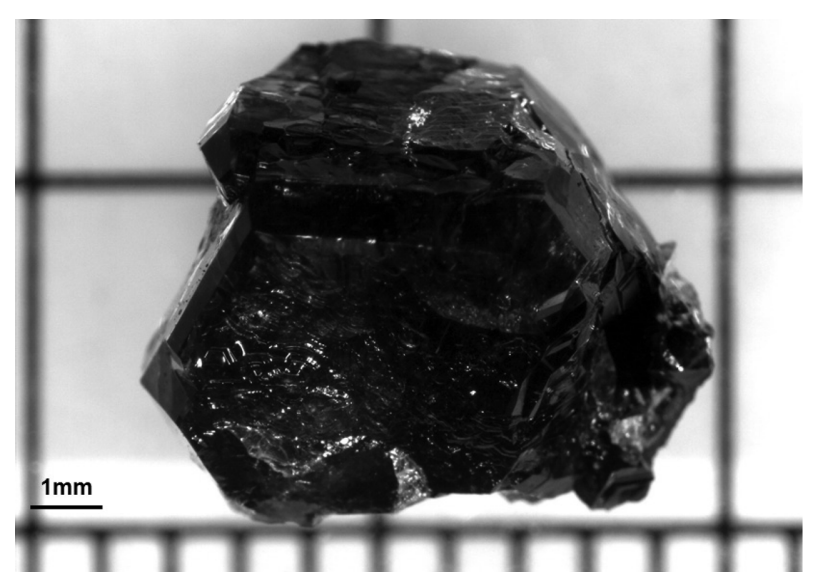

Fig. 3. Micrograph of as grown AlN crystal of a size of about $8 \mathrm{~mm}$. As shown below lines are the scale lines in $1 \mathrm{~mm}$. 


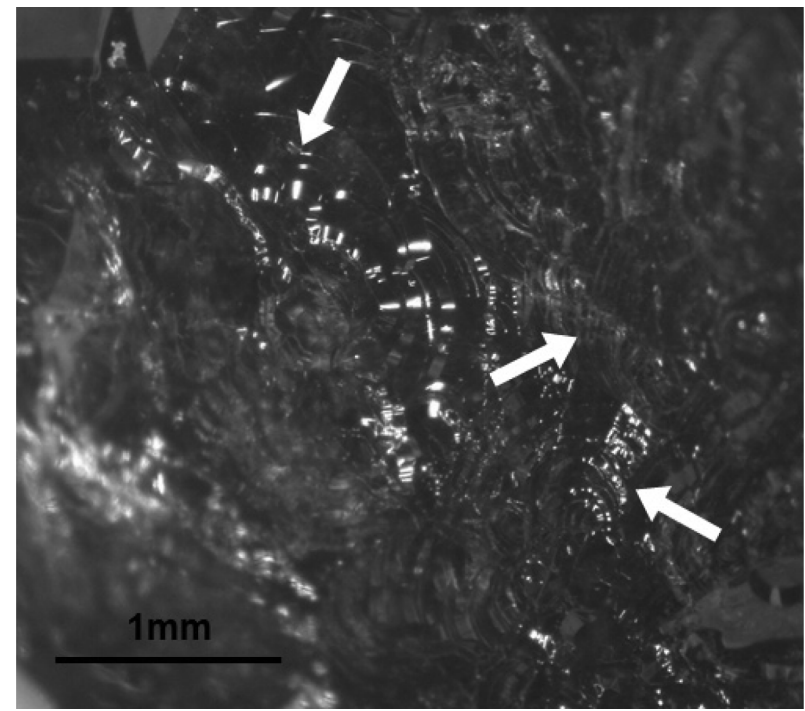

Fig. 4. Micrograph of spiral steps (as pointed by arrows, steps with narrow width) grown on as grown surface, c (0001) plane of AlN crystal. These steps were formed when the growth rate of each steps to perpendicular direction to them was faster than to the lateral direction.

로 사용한 결정의 facet이 잘 유지되었다고 판단되어 지 는데, 이는 결정의 크기에 따른 부분적인 과포화도의 차 이에서 오는 결과라고 사료된다. 즉, 결정의 크기가 커짐 과 동시에 성장 계면에서의 원자들의 공급 및 이동도가 감소되어 facet이 발달하는 면에 평행한 방향으로 성장 하는 lateral growth 양상으로 성장하는 것이 이상적인

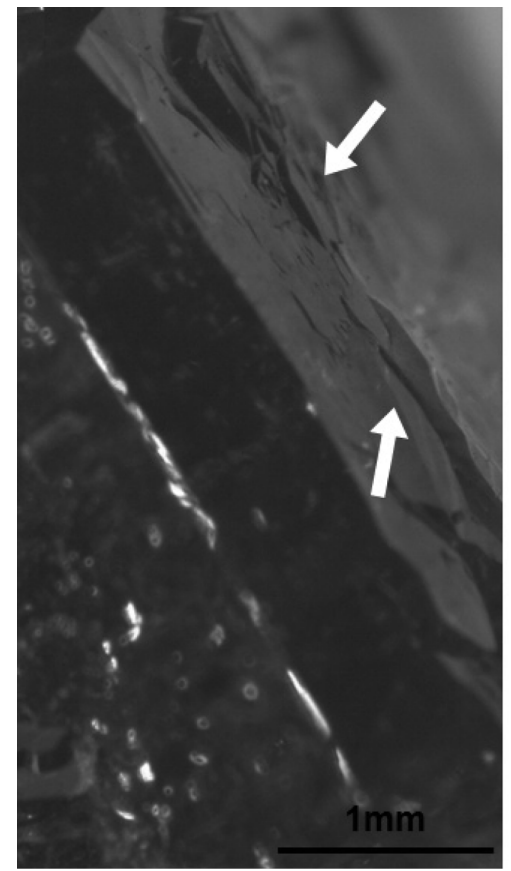

Fig. 5. Micrograph of irregular shaped steps (as pointed by arrows) grown on as grown surface, a (1000) plane of AlN crystal.

결정 성장 조건이다, 그러나, 원자들의 이동 속도가 빠르 게 되면 step 성장 양상으로 성장하기 보다는 facet면에 수직한 방향으로의 성장이 우선적으로 빠르기 때문에 평 활한 면으로 성장하지 못하는 결과[5]가 나타난 것으로 사료된다. 또한, 성장 결정의 결과에서 $\mathrm{AlN}$ 결정은 결정

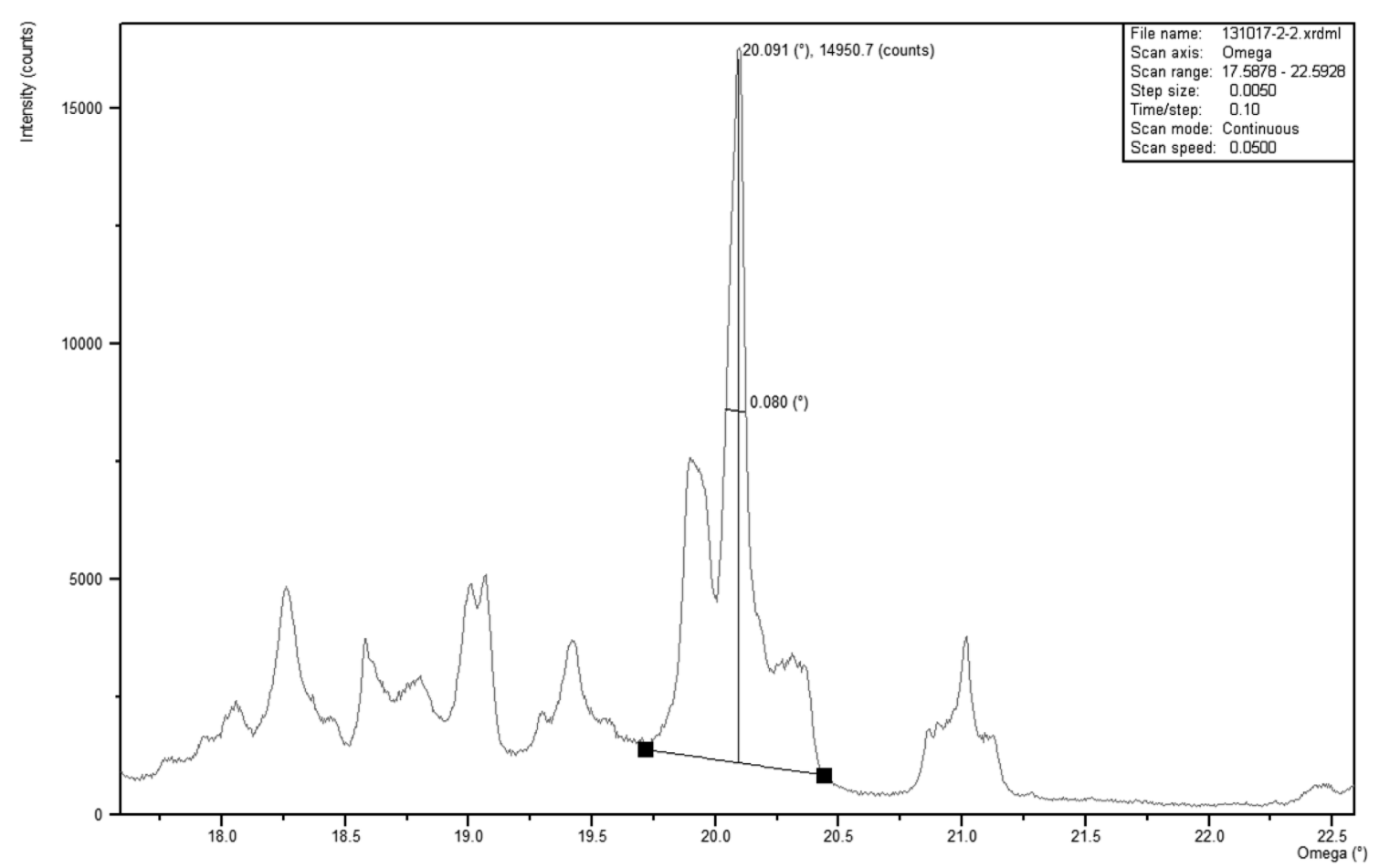

Fig. 6. DCXRD rocking curves from c (0001) plane of as grown AlN crystal. FWHM $=288$ arcsec. 
의 어느 일정 방향으로의 선택적인 성장 양상을 가지고 성장하기 보다는 입체 성장하는 양상을 보이고 있었음을 알 수 있었는데, 이는 앞에서 언급한 것처럼 성장 step 의 형성 속도보다 성장 step에 수직한 방향으로 성장하 는 양상으로 성장하기 때문으로 사료된다.

Fig. 4과 Fig. 5에 성장된 결정의 표면을 관찰한 광학 현미경 사진을 보였다. Fig. 4에서는 c면 상에 성장된 결정상을 보인 것으로 $\mathrm{c}$ 축 방향의 성장보다는 $\mathrm{a}$ 축 및 $\mathrm{b}$ 축 방향이 우선적으로 성장하는 양상을 보임으로서 위에 서 언급한 형태의 성장 스텝들이 관찰되고 있으며, 각각 의 spiral의 중심은 나선 전위가 있을 것으로 사료된다. Fig. 5에서 보이듯이, AlN 결정의 a-plane(1100) 면에서 는 이러한 성장 스텝이 발견되지 않고, 직선형의 성장스 텝이 발견되고 있고, 매우 평활한 facet 면 형태로 성장 되어야 하지만, 실험 결과 결정이 성장되는 온도가 다소 고온상태가 되면 성장 계면에서의 과포화도가 균일하지 못하기 때문에 부분적으로 평활한 facet 면과 step을 유 지하지 못하면서 성장되는 양상을 보이고 있다고 사료된 다[6].

Fig. 6는 성장된 AlN 단결정에 대하여 DCXRD를 통 한 rocking curve를 측정한 사진을 보인 것이다. 피크의 $\mathrm{FWHM}$ 값을 측정하여 성장된 결정의 결정성을 알아보 기 위한 것으로 약 $288 \mathrm{arcsec}$ 의 값을 얻었다. 피크의 저단부에서 split 현상이 보이는데, 이는 성장된 결정 내 에 defect의 존재에 의한 것, 또는 쌍결정(twin)의 형성 으로 보이며, 또한 표면에 형성된 나선 전위로 인하여 결정성이 감소한 $\mathrm{FWHM}$ 값이 얻어졌다고 사료된다.

\section{4. 결 론}

$\mathrm{AlN}$ 결정을 종자결정을 사용하지 않고 성장하여 연속
하여 결정을 대형화하는 공정을 적용하여 직경 $8 \mathrm{~mm}$ 정도의 결정을 성장할 수 있었다. 성장된 결정은 $\mathrm{c}$ 면상 에 spiral step이 존재함을 관찰하였으며, 이는 나선전위 로 인한 것으로 사료된다. $\mathrm{DCXRD}$ 를 통하여 결정의 품 질을 측정하였고, $\mathrm{FWHM}$ 값은 약 $288 \mathrm{arcsec}$ 의 값을 얻었다.

\section{감사의글}

본 연구는 산업통상부에서 주관하는 전략적핵심소재기 술개발사업(과제번호: 10043791)으로 수행되었습니다.

\section{참 고 문 헌}

[1] E.N. Mokhov, O.V. Avdeev, I.S. Barash, T. Yu. Chemekova, A.D. Roenkov, A.S. Segal, A.A. Wolfson, Yu. N. Makarov, M.G. Ramm and H. Helava, "Sublimation growth of AlN bulk crystals in Ta crucibles", J. of Crystal Growth 281 (2005) 93.

[2] S.M. Kang, "Step growth and defects formation on growth interface for SiC sublimation growth", J. Korean Cryst. Growth Cryst. Technol. 9 (1999) 558.

[3] S.M. Kang, "The study on the formation of growth steps in the sublimation growth of SiC single crystals", J. Korean Cryst. Growth Cryst. Technol. 11 (2001) 1.

[4] S.M. Kang, "Growth of AIN crystals by the sublimation process", J. Korean Cryst. Growth Cryst. Technol. 18 (2008) 68.

[ 5 ] P. Lua, J.H. Edgar, C. Cao, K. Hohn, R. Dalmau, R. Schlesser and Z. Sitar, "Seeded growth of AlN on SiC substrates and defect characterization", J. of Crystal Growth 310 (2008) 2464.

[6] S.M. Kang, "Morphological study on non-seeded grown AlN single crystals", J. Korean Cryst. Growth Cryst. Technol. 22 (2012) 265. 